\title{
Robust future changes in temperature variability under greenhouse gas forcing and the relationship with thermal advection
}

Article

Published Version

Holmes, C. R., Woollings, T., Hawkins, E. and de Vries, H. (2016) Robust future changes in temperature variability under greenhouse gas forcing and the relationship with thermal advection. Journal of Climate, 29 (6). pp. 2221-2236. ISSN 1520-0442 doi: https://doi.org/10.1175/JCLI-D-14-00735.1 Available at https://centaur.reading.ac.uk/48781/

It is advisable to refer to the publisher's version if you intend to cite from the work. See Guidance on citing.

Published version at: http://dx.doi.org/10.1175/JCLI-D-14-00735.1

To link to this article DOI: http://dx.doi.org/10.1175/JCLI-D-14-00735.1

Publisher: American Meteorological Society

All outputs in CentAUR are protected by Intellectual Property Rights law, including copyright law. Copyright and IPR is retained by the creators or other copyright holders. Terms and conditions for use of this material are defined in the End User Agreement. 


\section{CentAUR}

Central Archive at the University of Reading

Reading's research outputs online 


\title{
${ }^{\partial}$ Robust Future Changes in Temperature Variability under Greenhouse Gas Forcing and the Relationship with Thermal Advection
}

\author{
CAROLINE R. Holmes \\ School of Geosciences, University of Edinburgh, Edinburgh, United Kingdom \\ TiM WOOLLINGS \\ Atmospheric, Oceanic and Planetary Physics, University of Oxford, Oxford, United Kingdom \\ ED HAWKINS \\ National Centre for Atmospheric Science, Department of Meteorology, University of Reading, Reading, United Kingdom \\ HYLKE DE VRIES \\ Royal Netherlands Meteorological Institute, De Bilt, Netherlands
}

(Manuscript received 29 October 2014, in final form 7 June 2015)

\begin{abstract}
Recent temperature extremes have highlighted the importance of assessing projected changes in the variability of temperature as well as the mean. A large fraction of present-day temperature variance is associated with thermal advection, as anomalous winds blow across the land-sea temperature contrast, for instance. Models project robust heterogeneity in the twenty-first-century warming pattern under greenhouse gas forcing, resulting in land-sea temperature contrasts increasing in summer and decreasing in winter and the pole-toequator temperature gradient weakening in winter. In this study, future changes in monthly variability of nearsurface temperature in the 17-member ensemble ESSENCE (Ensemble Simulations of Extreme Weather Events under Nonlinear Climate Change) are assessed. In winter, variability in midlatitudes decreases whereas in very high latitudes and the tropics it increases. In summer, variability increases over most land areas and in the tropics, with decreasing variability in high latitude oceans. Multiple regression analysis is used to determine the contributions to variability changes from changing temperature gradients and circulation patterns. Thermal advection is found to be of particular importance in the Northern Hemisphere winter midlatitudes, where the change in mean state temperature gradients alone could account for over half the projected changes. Changes in thermal advection are also found to be important in summer in Europe and coastal areas, although less so than in winter. Comparison with CMIP5 data shows that the midlatitude changes in variability are robust across large regions, particularly high northern latitudes in winter and middle northern latitudes in summer.
\end{abstract}

\section{Introduction}

Robust regional and seasonal variations in the mean surface warming are projected for the twenty-first century (Collins et al. 2013) and have been observed in the

๑ Denotes Open Access content.

Corresponding author address: Caroline Holmes, Grant Institute, King's Buildings, West Mains Road, Edinburgh EH9 3JW, United Kingdom.

E-mail: caroline.holmes@ed.ac.uk recent observational record (Hartmann et al. 2013). These include winter Arctic amplification, enhanced warming over land (e.g., Boer 2011), and enhanced warming in the winter hemisphere. Near-surface Arctic amplification, particularly strong in autumn and winter, is largely related to sea ice changes since decreased cover in the summer months causes increased ocean heat uptake, resulting in increased heat fluxes from the ocean to the atmosphere in autumn and winter (Screen and Simmonds 2010). The land-sea warming ratio, although previously thought to result from the thermal inertia of the ocean, does not change noticeably over time and is therefore likely to be attributable instead to 
various other processes (Collins et al. 2013) such as different lapse rate feedbacks over land and ocean (e.g., Joshi et al. 2008).

However, for useful impacts assessment the mean temperature is not necessarily the most important parameter; recent extreme temperature events have highlighted the urgency of assessing whether the likelihood of such events changes in an anthropogenically forced world. Two examples are the 2003 European heat wave (Stott et al. 2004) and the very cold winter of 2010 across Europe (Cattiaux et al. 2010). For the European region, research into the mechanisms for changes in extreme hot days (Fischer and Schär 2009) and cold spells (de Vries et al. 2012; Peings et al. 2013) is ongoing. Changes in variability may be more important for temperature extremes than the well-documented changes in the mean, as suggested both by considerations from extreme value theory (Katz and Brown 1992) and climate model analysis (Schär et al. 2004).

Therefore a review of the projected global changes in temperature variability is timely. The aims of this paper are first to use both a single model ensemble and a multimodel ensemble to provide such a review, and second to quantify the relationship between these changes in variability and the heterogeneity of the warming pattern. The existing literature on this subject, and the proposed mechanism, is discussed below.

Some common features of changing variability have emerged in the literature. On interannual time scales there is evidence of decreasing variability of winter mean temperatures and increasing variability of summer mean temperatures in Europe (Rowell 2005; Scherrer et al. 2005). Gregory and Mitchell (1995) found that daily temperature variability in Europe also decreased in winter but increased in summer under doubling of $\mathrm{CO}_{2}$ in an atmosphere and slab ocean configuration of the Met Office Hadley Centre model. While this model at the time showed strong mean state biases, recent studies using state-of-the-art climate models and twenty-first-century forcing scenarios have concluded similarly for Europe; de Vries et al. (2012) found decreased winter daily temperature variability in a 17-member ensemble of ECHAM5/MPI-OM and Fischer and Schär (2009) found increasing daily temperature variability in summer in a multimodel ensemble of regional climate models. Ylhäisi and Räisänen (2014) found similar results for Europe, and decreases for the Northern Hemisphere midlatitudes as a whole, in daily temperature variability. However, the picture is not so robust everywhere (Ylhäisi and Räisänen 2014). For example, the Arctic response tends to be characterized by variability changes of the same sign as those in midlatitudes in early models with simple sea ice treatment (Stouffer and Wetherald 2007); in contrast, later models with ice dynamics and features such as sea ice leads show increasing variability in winter and decreasing variability in summer. It is important to note that models differ considerably in their representation of twentieth-century interannual temperature variability (Hawkins and Sutton 2012).

The dominant mechanisms driving temperature variability and its projected changes differ by region and season. In summer, radiative and land surface processes are thought to dominate. In particular, changes in surface heat balance (Gregory and Mitchell 1995) related to reduced soil moisture availability have been shown in several studies (Fischer and Schär 2009; Fischer et al. 2012; Seneviratne et al. 2006; Lenderink et al. 2007; Vidale et al. 2007) to be important in central Europe. Changes in the radiative balance associated with cloud cover (Pfahl and Wernli 2012; Lenderink et al. 2007) have also been discussed. For autumn and winter changes in thermal advection, specifically from changes in time-mean surface temperature gradients, have been proposed as a dominant mechanism (Gregory and Mitchell 1995; van Ulden and van Oldenborgh 2006; de Vries et al. 2012; Screen 2014). This has also been mentioned as a less important driver in summer (van Ulden and van Oldenborgh 2006; Lenderink et al. 2007). It is this mechanism that forms the focus of this study, and it is discussed further below.

Circulation patterns such as the North Atlantic Oscillation and synoptic patterns such as blocking have a strong influence on regional temperatures largely through thermal advection. For example, a winter blocking system over Europe brings cold air from the Arctic or the cold continental interior (e.g., Goubanova et al. 2010). In the United Kingdom, this is manifest as a relationship between central England temperature (Parker et al. 1992) and synoptic variability as characterized by either air source or geostrophic flow direction and strength (Parker 2009; Osborn et al. 1999). It may therefore be expected that changes in either circulation patterns or surface temperature gradients, together contributing to thermal advection, may contribute to changing variability.

This mechanism is potentially valid anywhere on the globe; land areas are generally warmer than ocean areas in summer and colder in winter (Figs. 1a,b; see Kang et al. 2015) and warm faster with climate change than ocean areas in both seasons, especially summer (Fig. 1c,d). Thus the heterogeneity of the warming pattern is such that the land-ocean temperature gradient strengthens in summer and weakens in winter (Fig. 1, lower panels). On the other hand, the Arctic is colder than the tropics year round, so that northern 
(a) Winter, mean T

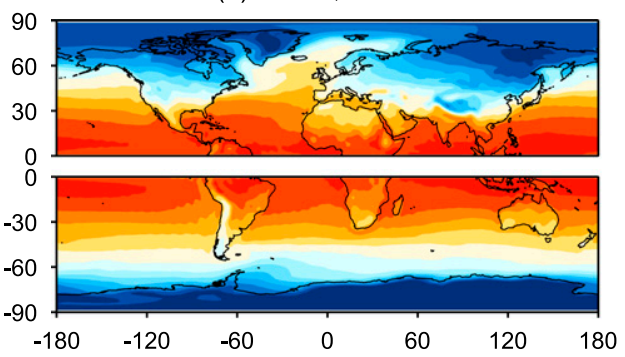

c) Winter, mean T change

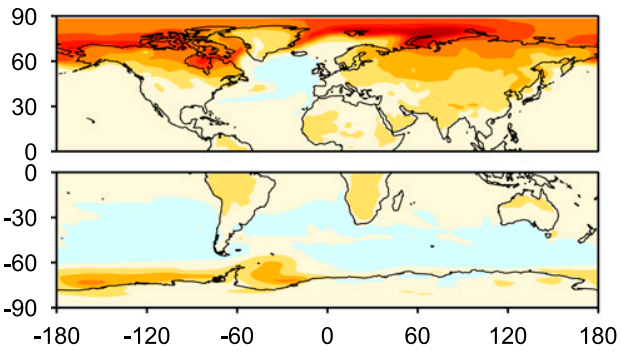

e) Winter, zonal gradient change

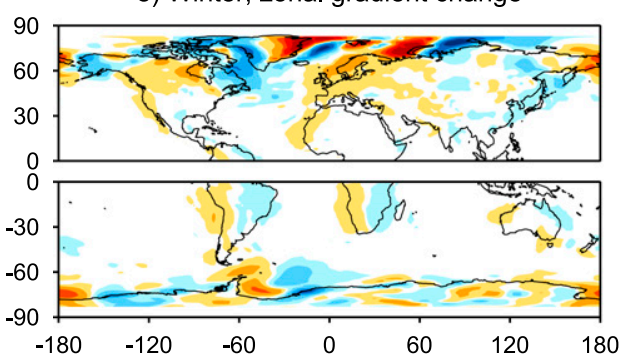

g) Winter, equator-to-pole gradient change
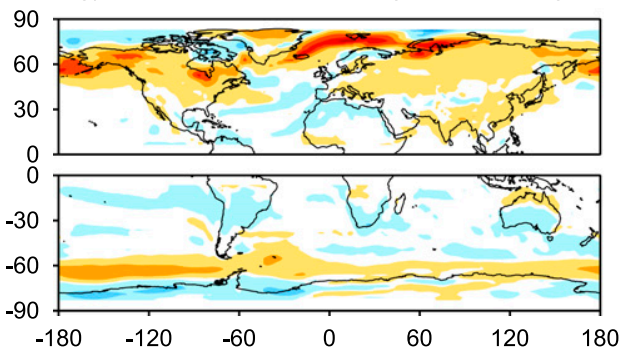

(b) Summer, mean T

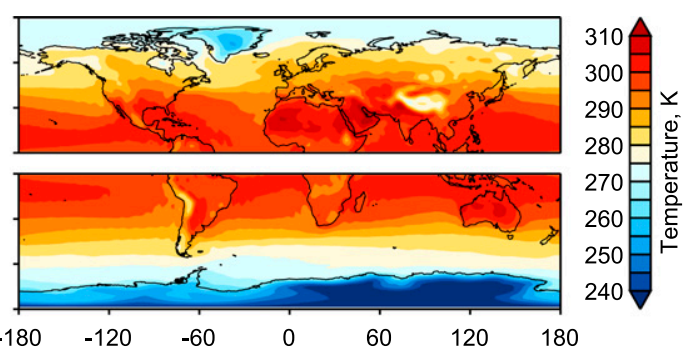

d) Summer, mean T change
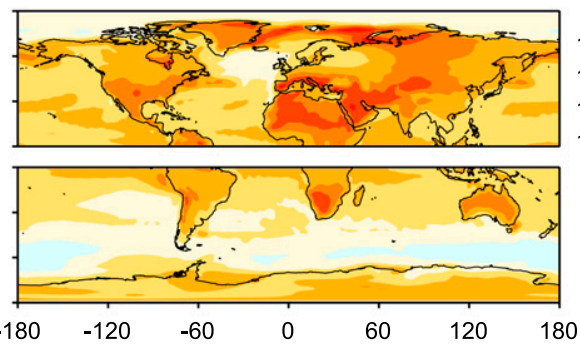

f) Summer, zonal gradient change
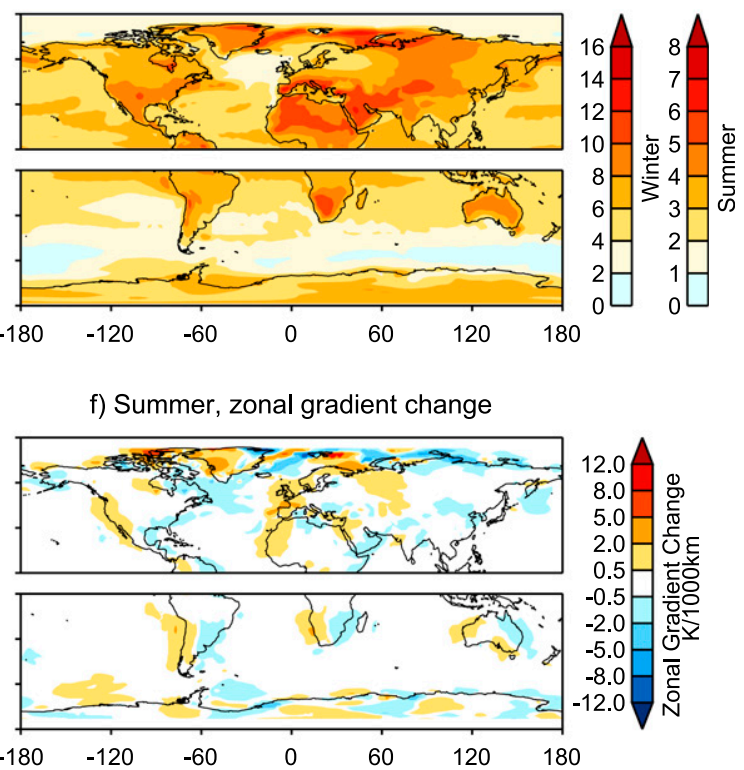

FIG. 1. (a),(b) ESSENCE seasonal-mean, ensemble-mean 2-m air temperature $(\bar{T})$ for winter and summer, respectively. (c),(d) The projected change FUT-C20 in ESSENCE seasonal-mean, ensemble-mean $\bar{T}$ for winter and summer, respectively. (e),(f) As above, but for zonal gradient $\partial \bar{T} / \partial x$, calculated over $18.75^{\circ}$ longitude. (g),(h) As above, but for equator-to-pole gradient $\partial \bar{T} / \partial|y|$, calculated over $11.25^{\circ}$ latitude. Gradients in $\mathrm{K}(1000 \mathrm{~km})^{-1}$.

polar amplification of warming (predominantly in the winter) weakens the time-mean meridional temperature gradient at $2 \mathrm{~m}, \partial \bar{T} / \partial|y|$ (Fig. $1 \mathrm{~g}$ ). Here, $|y|$ is distance from the equator, such that $\partial \bar{T} / \partial|y|$ is typically negative. Red shading in the figure, denoting an increase, is therefore a weakening of the gradient. Therefore, even unchanged wind patterns blowing across projected mean temperature gradients would cause widespread decreased variability in winter and increased variability in summer in or near coastal areas.

Thus, in Europe for example, the changes in surface temperature gradient (Fig. 1) are consistent with increases in summer variability and decreases in winter variability. Indeed, Gregory and Mitchell (1995) proposed that the changing land-sea temperature contrast was the key mechanism for simulated changes in winter 
variability and de Vries et al. (2012) used a crossmember regression in a single-model ensemble to show the role of zonal temperature gradients in projected winter changes in central Europe. Projected changes in the summer land-sea temperature difference over Australia have been shown to drive thermal advection changes contributing to enhanced temperature extremes (Watterson et al. 2008). Most recently, Arctic amplification and the reduction of the Northern Hemisphere meridional temperature gradient have been linked to reduced severity of cold days, and so to reduction of daily temperature variance (Screen 2014).

Changes in mean gradients and their impact on thermal advection therefore provide a possible physical mechanism behind changing temperature variability (de Vries et al. 2012; van Ulden and van Oldenborgh 2006). Circulation changes projected by global climate models would also impact thermal advection but there is more uncertainty as to the direction and causes of such changes than in the case of mean temperature gradients.

The first aim of this study is to examine the robustness of global projections for twenty-first-century daily and monthly temperature variability, and the spatial relationships of these projections to changing temperature gradients, both in the ESSENCE single model ensemble (Sterl et al. 2008; see below) and in the phase 5 of the Coupled Model Intercomparison Project (CMIP5) models (section 3; both datasets are introduced in section 2). The second goal is to quantify the effect of thermal advection on twentieth-century temperature anomalies in ESSENCE through the use of multiple linear regression (section 4), and finally to use this regression to investigate what proportion of projected changes in variability can be attributed to thermal advection. This study considers both winter and summer; thermal advection is generally assumed not to be a dominant driver of summer variability (as discussed above) and we test this assumption. There is also a particular focus on the midlatitude continents.

\section{Data}

\section{a. The ESSENCE ensemble}

Larger samples are needed for robust comparison of standard deviations than when comparing mean values. We therefore use a large ensemble to enable a rigorous assessment of changes in variability. Here we use data from the ESSENCE single model ensemble (Ensemble Simulations of Extreme Weather Events under Nonlinear Climate Change; Sterl et al. 2008). This consists of a 17-member ensemble of the ECHAM5/MPI-OM model, forced with observed forcings for 1950-2000 and with the SRES A1B emission scenario for 2001-2100. The ensemble is generated through perturbation of the initial atmospheric conditions only, and can be expected to effectively sample the variability in the climate system. The ECHAM5/MPI-OM coupled model used in the ESSENCE project was shown to produce a good representation of observed global SLP patterns over the twentieth century (van Ulden and van Oldenborgh 2006).

Two periods are isolated for comparison; a twentiethcentury control period C20 (December 1950-July 1990) and a future period FUT (December 2060-July 2100). The seasons December-February (DJF) and JuneAugust (JJA) are considered. Because of the seasonality discussed in the introduction, the periods discussed hereafter are winter (Northern Hemisphere DJF and Southern Hemisphere JJA) and summer (vice versa).

The data used are daily mean fields of 2-m air temperature $T$ and sea level pressure (SLP), computed into monthly averages where required, and monthly mean sea ice concentration (SIC; as a fraction of sea area in the grid box) and snow depth (m). All data are global and on an N48 Gaussian grid $\left(1.875^{\circ}\right.$ latitude $\times 1.865^{\circ}$ longitude).

\section{b. CMIP5}

Data from phase 5 of the Coupled Model Intercomparison Project (CMIP5) multimodel ensemble is also analyzed. The models considered are listed in Table 1; all model output is interpolated to a regular $2.5^{\circ}$ grid prior to analysis, and only monthly-mean nearsurface air temperature (TAS) is utilized. The model runs considered are forced with observed forcings in the twentieth century and representative concentration pathway 4.5 (RCP4.5) in the twenty-first century.

CMIP5 is made up of a newer generation of climate models than ECHAM5/ MPI-OM, which was part of the previous phase (CMIP3). RCP4.5 corresponds to a weaker forcing than the SRES A1B scenario of CMIP3, if anything being more comparable to SRES B1 (van Vuuren et al. 2011). However, identifying the changes that are both robust across the CMIP5 ensemble and consistent between the CMIP5 and ESSENCE ensembles gives confidence in the qualitative nature of the changes seen, since they are found in the response to different levels of forcing, in different models, and with different initial conditions. The C20 and FUT periods are used as previously defined.

\section{c. Processing}

An underlying trend in a data series serves to inflate its true intrinsic variability (Scherrer et al. 2005) so such trends should be removed prior to conducting variance 
TABLE 1. List of CMIP5 models used (page 1 of 2). Expansions of acronyms are available online at http://www.ametsoc.org/ PubsAcronymList.

\begin{tabular}{|c|c|}
\hline Model name & Institution \\
\hline ACCESS1.0 & $\begin{array}{l}\text { CSIRO (Commonwealth Scientific and Industrial Research Organization, Australia), } \\
\text { and BOM (Bureau of Meteorology, Australia) }\end{array}$ \\
\hline ACCESS1.3 & $\begin{array}{l}\text { CSIRO (Commonwealth Scientific and Industrial Research Organization, Australia), } \\
\text { and BOM (Bureau of Meteorology, Australia) }\end{array}$ \\
\hline BCC-CSM1.1 & Beijing Climate Center, China Meteorological Administration \\
\hline BCC-CSM1.1-m & Beijing Climate Center, China Meteorological Administration \\
\hline BNU-ESM & $\begin{array}{l}\text { College of Global Change and Earth System Science, } \\
\text { Beijing Normal University }\end{array}$ \\
\hline CanESM2 & Canadian Centre for Climate Modeling and Analysis \\
\hline CCSM4 & National Center for Atmospheric Research (NCAR) \\
\hline CESM1-BGC & National Science Foundation, Department of Energy, NCAR \\
\hline CESM1-CAM5 & National Science Foundation, Department of Energy, NCAR \\
\hline $\mathrm{CMCC}-\mathrm{CM}$ & Centro Euro-Mediterraneo per I Cambiamenti Climatici \\
\hline CMCC-CMS & Centro Euro-Mediterraneo per I Cambiamenti Climatici \\
\hline CNRM-CM5 & $\begin{array}{l}\text { Centre National de Recherches Meteorologiques/Centre Europeen de Recherche et } \\
\text { Formation Avancees en Calcul Scientifique }\end{array}$ \\
\hline CSIRO-Mk3.6.0 & CSIRO in collaboration with the Queensland Climate Change Centre of Excellence \\
\hline EC-Earth23 & EC-EARTH consortium \\
\hline FGOALS-g2 & $\begin{array}{l}\text { LASG, Institute of Atmospheric Physics, Chinese Academy of Sciences; and CESS, } \\
\text { Tsinghua University }\end{array}$ \\
\hline FIO-ESM & The First Institute of Oceanography, SOA, China \\
\hline GFDL-CM3 & Geophysical Fluid Dynamics Laboratory (GFDL) \\
\hline GFDL-ESM2G & Geophysical Fluid Dynamics Laboratory \\
\hline GFDL-ESM2M & Geophysical Fluid Dynamics Laboratory \\
\hline GISS-E2-H-CC & NASA Goddard Institute for Space Studies \\
\hline GISS-E2-H & NASA Goddard Institute for Space Studies \\
\hline GISS-E2-Hp2 & NASA Goddard Institute for Space Studies \\
\hline GISS-E2-Hp3 & NASA Goddard Institute for Space Studies \\
\hline GISS-E2-R-CC & NASA Goddard Institute for Space Studies \\
\hline GISS-E2-R & NASA Goddard Institute for Space Studies \\
\hline GISS-E2-Rp2 & NASA Goddard Institute for Space Studies \\
\hline GISS-E2-Rp3 & NASA Goddard Institute for Space Studies \\
\hline HadGEM2-AO & National Institute of Meteorological Research/Korea Meteorological Administration \\
\hline HadGEM2-CC & Met Office Hadley Centre \\
\hline HadGEM2-ES & Met Office Hadley Centre \\
\hline INM-CM4 & Institute for Numerical Mathematics \\
\hline IPSL-CM5A-LR & Institut Pierre-Simon Laplace \\
\hline IPSL-CM5A-MR & Institut Pierre-Simon Laplace \\
\hline IPSL-CM5B-MR & Institut Pierre-Simon Laplace \\
\hline MIROC-ESM & $\begin{array}{l}\text { Atmosphere and Ocean Research Institute (The University of Tokyo), National Institute } \\
\text { for Environmental Studies, and Japan Agency for Marine-Earth Science and Technology }\end{array}$ \\
\hline MIROC-ESM-CHEM & $\begin{array}{l}\text { Atmosphere and Ocean Research Institute (The University of Tokyo), National Institute } \\
\text { for Environmental Studies, and Japan Agency for Marine-Earth Science and Technology }\end{array}$ \\
\hline MIROC5 & $\begin{array}{l}\text { Atmosphere and Ocean Research Institute (The University of Tokyo), National Institute } \\
\text { for Environmental Studies, and Japan Agency for Marine-Earth Science and Technology }\end{array}$ \\
\hline MPI-ESM-LR & Max Planck Institute for Meteorology (MPI-M) \\
\hline MPI-ESM-MR & Max Planck Institute for Meteorology (MPI-M) \\
\hline MRI-CGCM3 & Meteorological Research Institute \\
\hline NorESM1-M & Norwegian Climate Centre \\
\hline NorESM1-ME & Norwegian Climate Centre \\
\hline
\end{tabular}

analysis, particularly for variables such as surface air temperature where strong trends exist. Fischer and Schär (2009) go further by decomposing daily variability into "interannual variability, intraseasonal variability, and variability induced by the seasonal cycle" to enable thorough understanding of the nature of changes.
In this study, the 40-yr linear trend in ensemble-mean (for ESSENCE; for CMIP5, each model is treated individually), seasonal-mean gridpoint temperature is removed for each period, thus discarding year-to-year temperature variability arising from the linear warming trend but retaining that which may result from persistent 
a) Winter Control SD

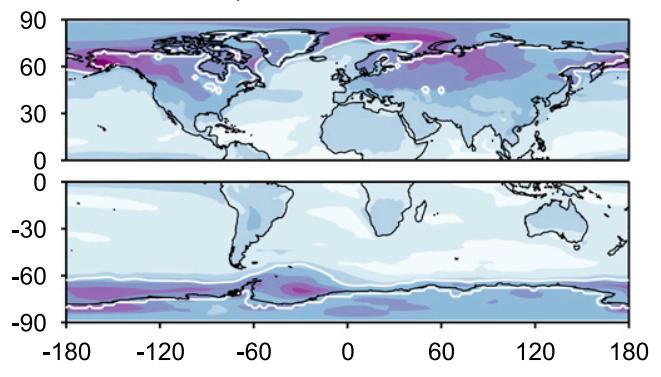

c) Winter SD change

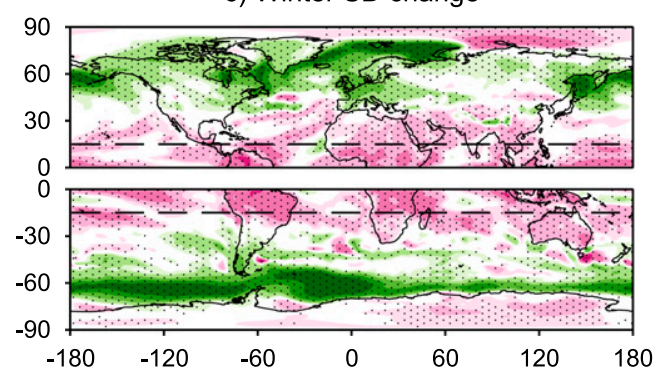

b) Summer Control SD
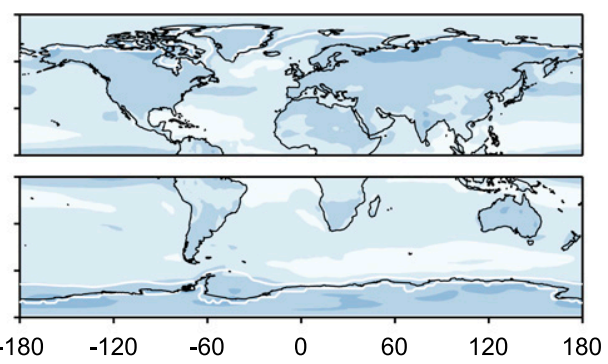

d) Summer SD change

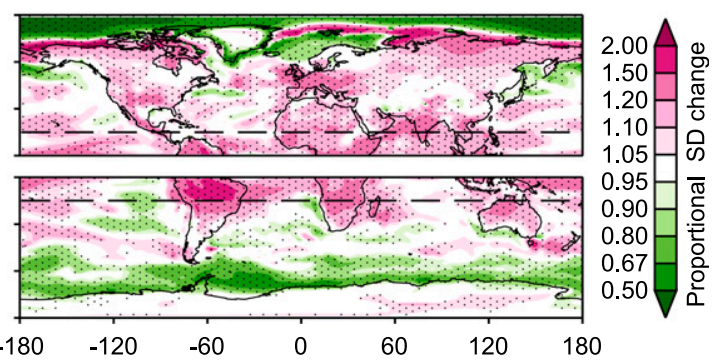

FIG. 2. (a),(b) $\sigma\left(T_{\mathrm{C} 20}^{\prime}\right)$, the standard deviation of ESSENCE monthly temperatures in C20 (shading) and ESSENCE climatological ice edge ( $15 \%$ concentration contour) in the relevant season (white contour). (c),(d) Projected twenty-first-century change in variability quantified by the ratio $\sigma\left(T_{\mathrm{FUT}}^{\prime}\right) / \sigma\left(T_{\mathrm{C} 20}^{\prime}\right)$. Stippling where 12 ensemble members ( $>67 \%$ of ensemble) agree with ensemble mean on sign of change.

circulation anomalies. In addition, it is desired to discard changes in variability brought about by changes in the seasonal cycle alone. Therefore the gridpoint periodmean for each calendar month is removed from each data point in the monthly time series after detrending.

\section{Temperature variability and projected changes}

\section{a. Control period variability in ESSENCE}

Much of the variability in circulation acts on submonthly time scales, so that thermal advection influences might be expected to be strongest at short time scales. However, daily data are very noisy and other processes also modify the temperature variability. Moreover, it is persistent anomalies that can have the strongest impacts on health and agriculture, as well as possibly contributing to climate feedbacks. Therefore, it is of merit to look at longer time scales, and so the analysis that follows will focus on monthly data. Using monthly data has the added benefit of allowing direct comparison with CMIP5 data.

The global map of monthly temperature variability in ESSENCE in the C20 period is presented in the top panels of Fig. 2, for (a) winter and (b) summer. Variability is quantified by $\sigma\left(T_{\mathrm{C} 20}^{\prime}\right)$, the standard deviation of all monthly temperature anomalies taken across the full ensemble after removing the trend and seasonal cycle. Winter daily temperature variability in Europe was shown in de Vries et al. (2012) to compare very well with ERA-40 reanalysis data even though Europe is a particularly hard area to model. However, different climate models show very varied twentieth-century interannual TAS variability (Hawkins and Sutton 2012) which must be borne in mind when interpreting studies such as this.

Temperature variability is highest in the winter, especially in mid- to high-latitude land areas in the Northern Hemisphere. It is also higher over sea icecovered areas such as east of the Antarctic peninsula and large regions of the Arctic Ocean than over open ocean (Stouffer and Wetherald 2007) as seen by the location of the seasonal-mean ice edge $(15 \%$ contour of seasonal mean ice cover; white contour in Fig. 2).

\section{b. Change in temperature variability in ESSENCE}

The change in temperature variability, quantified as the ratio $\sigma\left(T_{\mathrm{FUT}}^{\prime}\right) / \sigma\left(T_{\mathrm{C} 20}^{\prime}\right)$, is presented in the second panel of Fig. 2. Proportional changes are presented due to their relationship to the $\mathrm{F}$ test for statistical significance of changes in variability (Barlow 1989). In the Northern Hemisphere extratropics there is a notable seasonality to the response; variability generally decreases in winter and increases in summer. In the Arctic Ocean the opposite is broadly true, although local behavior varies. Elsewhere this seasonality is not evident; the standard deviation increases in the tropics and decreases in the Southern Ocean in both seasons. Regions 
a) DJF High Arctic $(80 \mathrm{~N}+)$

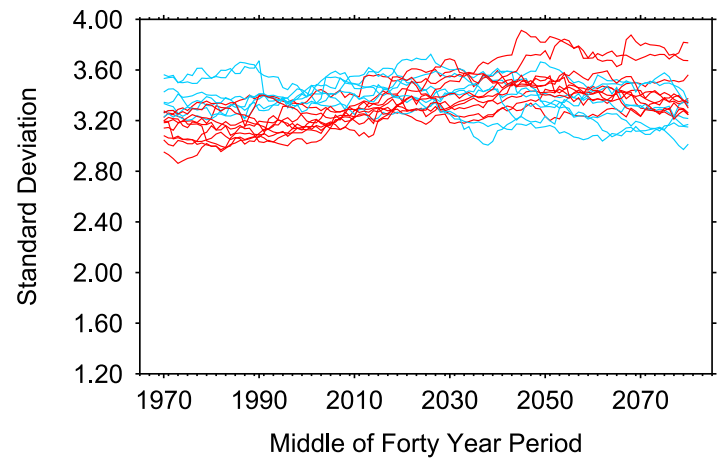

c) DJF Europe (10W-40E,35-70N)

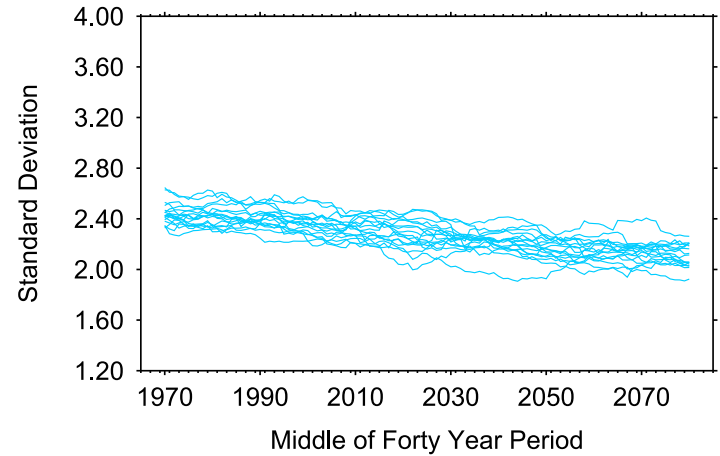

f) JJA Southern Ocean (50-70S)

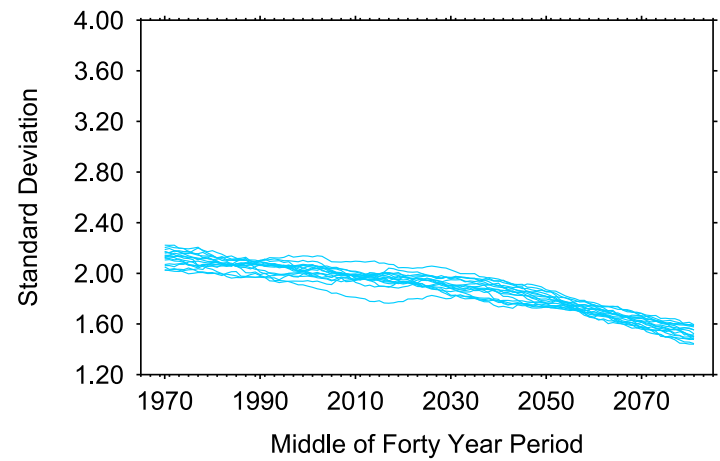

b) JJA High Arctic $(80 \mathrm{~N}+)$

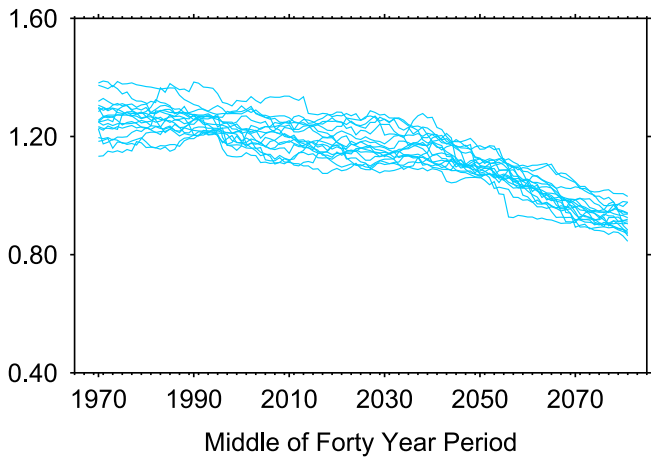

d) JJA Europe (10W-40E,35-70N)

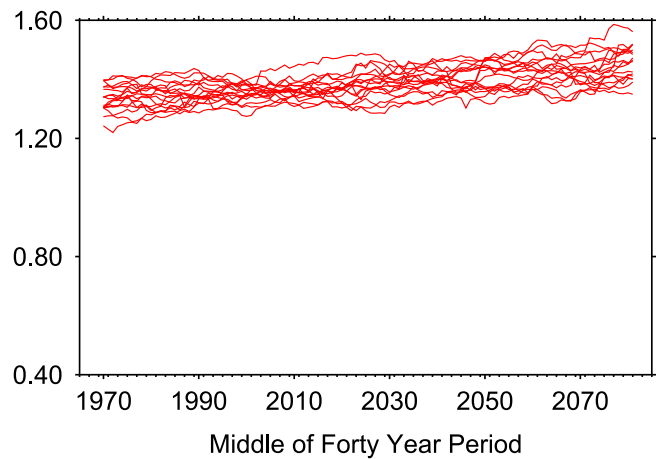

e) DJF Southern Ocean (50-70S)

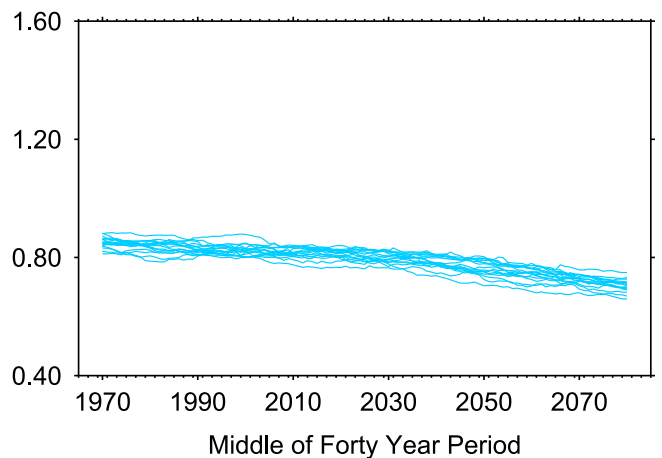

FIG. 3. The emergence of the variability signal in the 17 ensemble members of ESSENCE in (left) winter and (right) summer. Each line resembles an ensemble member; red indicates an increase, blue indicates a decrease. The time series is the square root of the regional mean of the variance of monthly mean temperatures, for the 40 -yr period centered on the given year. The trend and seasonal cycle of the ensemble mean is removed prior to analysis (see text).

where 12 members ( $67 \%$ of the ensemble) agree on the sign of change are stippled in Figs. $2 \mathrm{c}$ and $2 \mathrm{~d}$; this constitutes $75 \%$ of grid points where the given sign of variability change is "likely" in IPCC terminology. When the condition enforced is that $90 \%$ of the ensemble must agree (IPCC "very likely"), $30 \%$ of all grid points show ensemble agreement.

Because of the large spatial scales of changes of a given sign, it is reasonable to consider the regional average standard deviation over the full 151-yr period of ESSENCE to give insight into how the signal develops and how it is related to the ensemble spread. Figure 3 displays time series of 40-yr running $\sigma$ averaged over three representative regions: Europe, the Arctic Ocean, and the Southern Ocean. These time series reinforce some points from Fig. 2; first, the seasonal dependence of both initial variability and response in variability is evident in all three regions. 
a) Winter Control SD

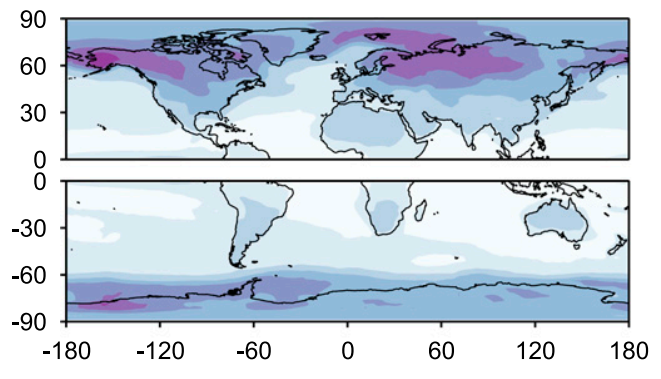

c) Winter SD change

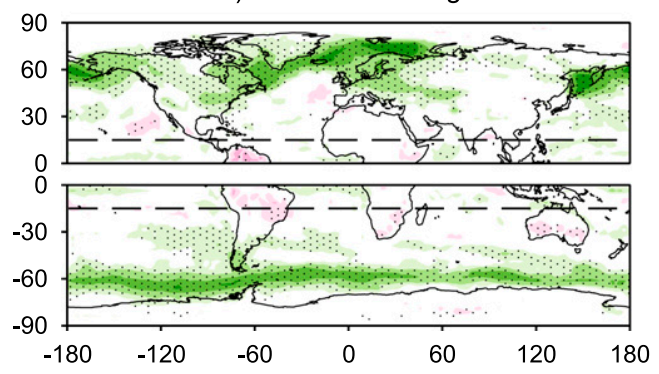

b) Summer Control SD
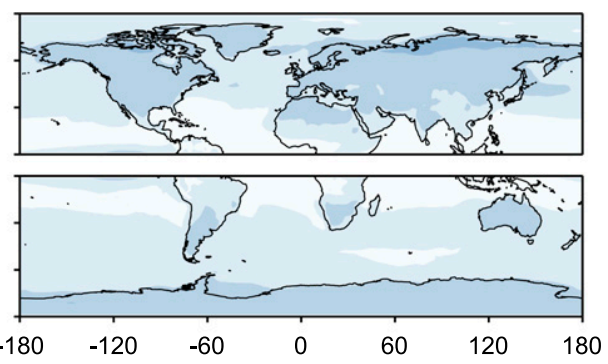

d) Summer SD change

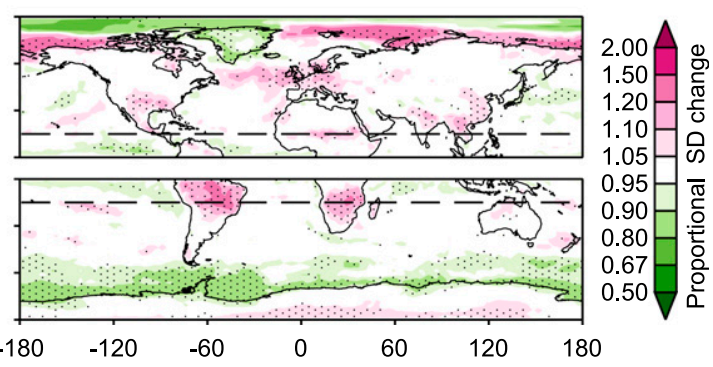

FIG. 4. (a),(b) Standard deviation of CMIP5 monthly temperatures in the control period. (c),(d) Projected twentyfirst-century change in variability quantified by the ratio $\sigma\left(\mathrm{TAS}_{\mathrm{FUT}}\right) / \sigma\left(\mathrm{TAS}_{\mathrm{C} 20}\right)$. The gridpoint trend and seasonal cycle is removed for each model prior to analysis. The data shown are the medians of the values in the multimodel ensemble; the median is calculated at separately each grid point. Stippling shows where $>67 \%$ of the multimodel ensemble agrees on sign of change.

Summer variability (right panels) is much lower, and better constrained, than winter variability (left panels), enabling the signal to emerge sooner. In Europe, the ensemble members unanimously agree on a summer increase in variability, and on a winter decrease. The time series demonstrate the large spread in the ensemble representation of variability, particularly in winter, demonstrating the need for use of a large ensemble or long periods for analysis. Note that even in the summer Arctic, where the signal is strongest, it does not "emerge" from the ensemble noise until the middle of the twenty-first century.

When similar analysis is conducted on the CMIP5 models (not shown), there is strong evidence of the effect of removing the seasonal cycle and trend. For five of the models, leaving in the seasonal cycle produces dramatic increases in DJF variability at the end of the twenty-first century, while leaving in the trends produces similar increases midcentury. Changing seasonality is therefore a cause of changes in monthly variability and of intermodel differences.

\section{c. Comparison with CMIP5}

Figure 4 displays $\sigma\left(\mathrm{TAS}_{\mathrm{C} 20}\right)$ and $\sigma\left(\mathrm{TAS}_{\mathrm{FUT}}\right) / \sigma\left(\mathrm{TAS}_{\mathrm{C} 20}\right)$ for the CMIP5 models; $\sigma$ is calculated as the median of the model standard deviations at each grid point, after removing the linear trend in seasonal mean temperature and the seasonal cycle for each model. Globally, ESSENCE variability in the control period is well representative of that in the CMIP5 ensemble (cf. Fig. 2). This is true despite the coarser grid in the CMIP5 data, which might lead to the measured variability being lower (Hawkins and Sutton 2012). ESSENCE variability is slightly higher than that in the CMIP5 median model over the tropical Pacific and other regions of the tropics in both seasons, a difference likely due to differences in ENSO representation. There are also differences in the Barents Sea and Southern Ocean, likely related to sea ice representation. Finally, while in the time-processed data shown (time and seasonal cycle removed) the two datasets generally agree over Antarctica, this was not the case for the raw data; in summer the standard deviation of temperatures in ESSENCE was approximately half that in the CMIP5 median model. This discrepancy was found largely to result from different representations of the seasonal cycle across the CMIP5 ensemble. However, Antarctica is not a key region of interest for this study and so is not discussed further.

The direction of change is robust between the two datasets except for two regions, as seen by again comparing Figs. 4 and 2. The first of these is the equatorial Pacific, in both seasons, which is again likely to be due to disagreement on ENSO processes between the 
models. The second is the marginal ice zone in the Barents Sea in summer, which is likely to be due to differences in sea ice processes and melt. Overall, projected changes in ESSENCE are stronger and more robust than in the CMIP5 ensemble median, particularly in the tropics. This is perhaps unsurprising, but points to the role of model uncertainty rather than long-time-scale internal variability for the CMIP5 model spread.

For the regions of particular interest in this study, namely midlatitude continents, the two datasets show strong agreement on the magnitude of control period variability and on the sign of change, with the exception of the Eurasian continental interior. This provides encouragement for performing further analysis in ESSENCE only.

\section{d. Qualitative relationship with temperature gradients}

The changes in variability found in response to greenhouse gas forcing (outlined above) are consistent with a relationship with temperature gradients, as follows.

In the Northern Hemisphere in winter, the dominant, most spatially coherent signal is a widespread increase in $\partial \bar{T} / \partial|y|$, that is, a weakening of the meridional temperature gradient between $35^{\circ}$ and $80^{\circ} \mathrm{N}$ (Fig. $1 \mathrm{~g}$ ). There is also a widespread weakening of the zonal gradients across the coasts due to changes in the land-sea contrast. It should be noted that on the west coasts of Europe and North America, the land-sea contrast effect spreads some way inland (Figs. 1c,e), for example in Europe $\left(10^{\circ} \mathrm{W}-30^{\circ} \mathrm{E}\right)$, probably due to the moderating oceanic influence on western European climate. In general therefore, advection-driven variability would be expected to decrease, consistent with the overall changes found above.

In the Northern Hemisphere in summer, land-sea contrasts increase (gradients strengthen) and additionally in southern and central Europe there is a strengthening of the meridional gradient due to the enhanced warming over Spain and the Mediterranean coast (Figs. 1f,h). Advection-driven variability would therefore be expected to increase.

In the Southern Hemisphere, there are no large zonally extending continents in the midlatitudes so the land-sea contrast is evident only locally. The meridional gradient signal is a weakening over ocean poleward of $60^{\circ} \mathrm{S}$ and a strengthening equatorward of here. The decrease in variability in the high-latitude ocean in both seasons is consistent with decreasing temperature gradients, although this could also be directly attributable to Antarctic sea ice, which is projected by the ESSENCE ensemble to decrease.

\section{Reconstruction of temperature variability}

\section{a. Multiple regression model}

To quantify the relationship between variability and thermal advection, and to investigate what portion of the changes discussed above can be attributed to changing temperature gradients and circulation patterns, we construct a multiple regression model. The variables considered are monthly mean temperature anomalies $T^{\prime}$ (processing as described above), climatological mean temperature gradients $\partial \bar{T} / \partial y$ and $\partial \bar{T} / \partial x$, and geostrophic wind anomalies $u_{g}^{\prime}$ and $v_{g}^{\prime}$. Use of geostrophic winds follows van Ulden and van Oldenborgh (2006) and de Vries et al. (2012); the components are calculated from ESSENCE SLP poleward of $15^{\circ}$ latitude (equatorward of here geostrophic balance is not a valid approximation), assuming constant density of $1.2 \mathrm{~kg} \mathrm{~m}^{-3}$ and Coriolis parameter $f$ calculated by latitude. Use of geostrophic winds is designed to capture the large-scale flow; however, in regions where geostrophic winds deviate significantly from the nearsurface wind speed, this can be expected to limit the utility of the model. Regions where this is observed include the Tibetan Plateau, Greenland, and the Andes (not shown).

Gradients in both SLP and $T$ are calculated over 11 grid points in the $x$ direction $\left(18.75^{\circ}\right.$ longitude) and 7 grid points in the $y$ direction $\left(11.25^{\circ}\right.$ latitude). These spatial scales are similar to those in van Ulden and van Oldenborgh (2006) and de Vries et al. (2012). A simple point difference is used such that, for example,

$$
\frac{\partial T}{\partial x_{i, j}}=\frac{T_{i+5, j}-T_{i-5, j}}{x_{i+5, j}-x_{i-5, j}},
$$

where the subscripts $i$ and $j$ are gridpoint indices in the zonal and meridional directions.

The variables are related using the multiple regression model

$$
T^{\prime}=\left(A u_{g}^{\prime} \frac{\partial \bar{T}}{\partial x}+B v_{g}^{\prime} \frac{\partial \bar{T}}{\partial y}\right)+\epsilon \equiv T_{\text {lin }}^{\prime}+\epsilon
$$

at each grid point, where $\epsilon$ is the residual. The regression is applied in the $\mathrm{C} 20$ period to obtain the regression coefficients $A$ and $B$ at each grid point.

More advanced methods in the calculation of the temperature gradient (such as averaging over a domain) were found not to affect the results. Likewise, a sensitivity test using geostrophic height at $850 \mathrm{hPa}$ to calculate the winds reduced the fraction of variance explained by the regression model in general. Therefore SLP was used. 
a) Winter Correlation
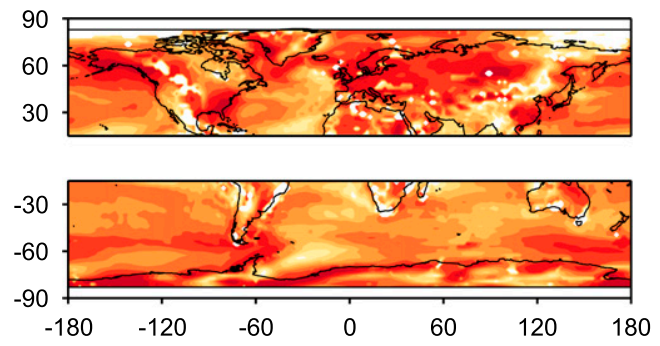

c) Winter SD change C20 u, FUT $\nabla T$
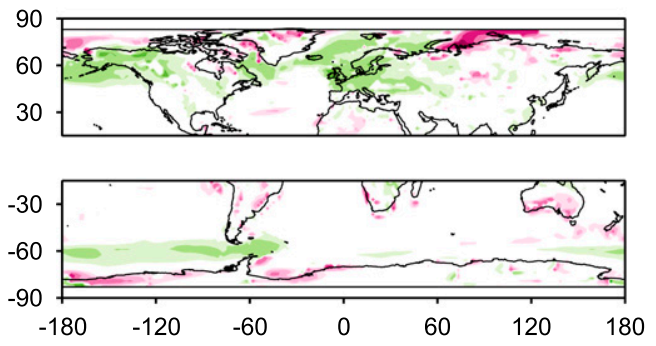

e) Winter fraction of change explained, N. America

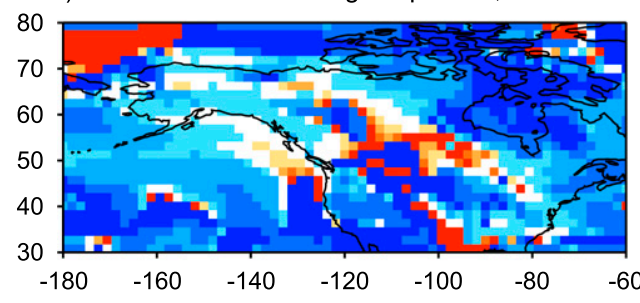

g) Winter fraction of change explained, Europe

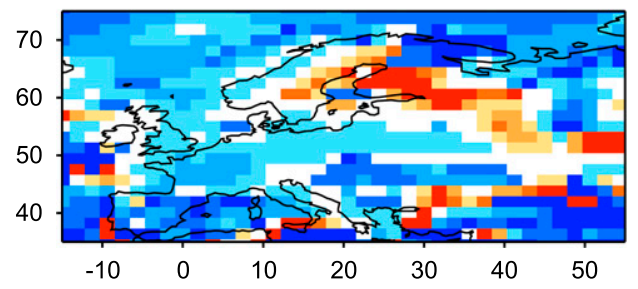

b) Summer Correlation
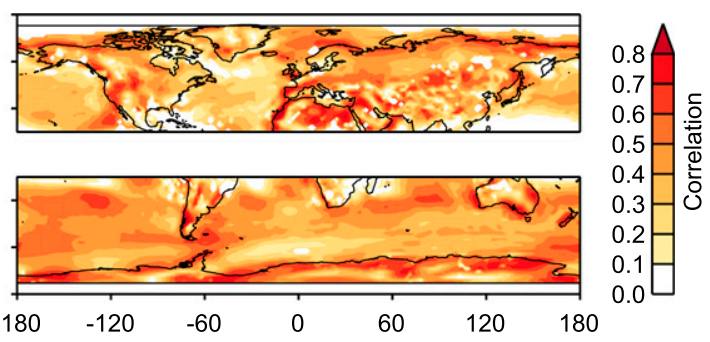

d) Summer SD change C20 u, FUT $\nabla T$
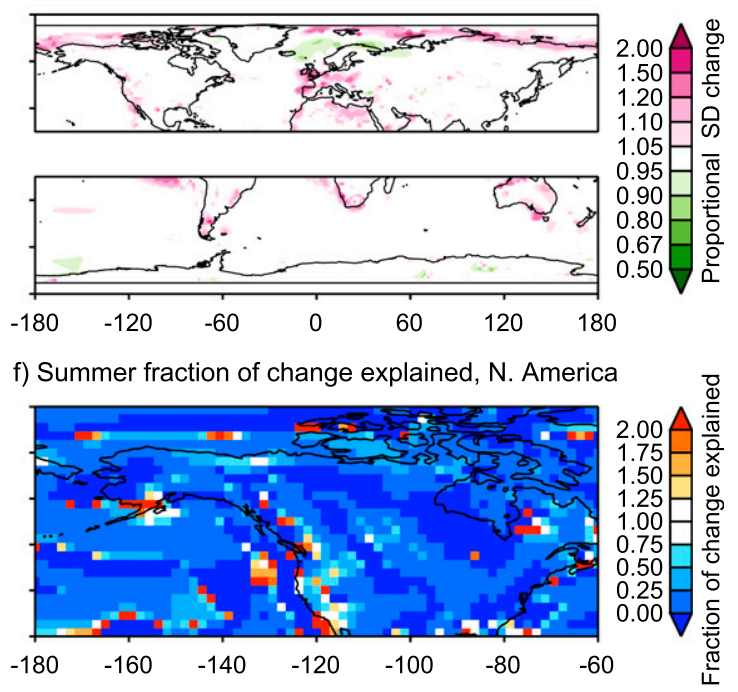

h) Summer fraction of change explained, Europe

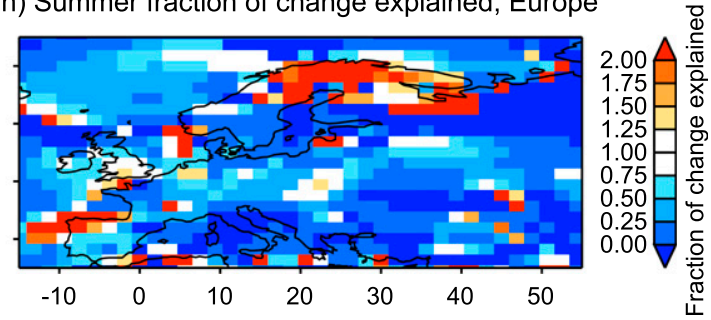

FIG. 5. (a),(b) The correlation of $T_{\mathrm{C} 20}^{\prime}$ with $T_{\text {lin }}^{\prime}$ for winter and summer. (c),(d) The change of standard deviation in the regression model quantified as $\sigma\left(T 3_{\nabla T}^{\prime}\right) / \sigma\left(T_{\mathrm{C} 20}^{\prime}\right)$. All data are monthly. (e)-(h) The fraction of change captured by the linear model; $\left[\sigma\left(T 3_{\nabla T}^{\prime}\right)-\sigma\left(T_{\mathrm{C} 20}^{\prime}\right)\right] /\left[\sigma\left(T 3_{\mathrm{FUT}}^{\prime}\right)-\sigma\left(T_{\mathrm{C} 20}^{\prime}\right)\right]$. Full details of notation can be found in Table 2 . Here and in subsequent figures, data are not available for very high latitudes, where the tight grid spacing is deemed to make the scales of the zonal gradient calculation inappropriate, or the tropics, where the geostrophic assumption is invalid. Therefore these areas are excluded from the plots.

\section{b. Fraction of variance explained}

The correlation coefficient can be viewed as an indicator of the goodness of fit of the regression. The regression model above equates a temperature anomaly with selected terms from the tendency equation for temperature, so neglecting temporal variability in temperature gradients as well as thermodynamic effects (as discussed in the introduction). Thus the correlation coefficient quantifies the ability of thermal advection acting across mean temperature gradients to explain temperature anomalies. Figures $5 \mathrm{a}$ and $5 \mathrm{~b}$ show the correlation coefficient in both seasons. Correlations are generally higher in winter, particularly in the Northern Hemisphere. Correlations in winter exceed 0.7 in regions such as western Europe, Alaska, and the eastern seaboard of North America; equivalently, $50 \%$ of temperature variance in these regions can be explained by 
TABLE 2. The notation for temperature anomalies in the linear model discussion.

\begin{tabular}{ll}
\hline \hline$T_{\mathrm{C} 20}^{\prime}$ & \multicolumn{1}{c}{ ESSENCE temperatures, C20 period } \\
\hline$T_{\mathrm{FUT}}^{\prime}$ & ESSENCE temperatures, FUT period \\
$T_{\text {lin }}^{\prime}$ & Linear fit to $T_{\mathrm{C} 20}^{\prime}$ \\
$\epsilon$ & Residual $T_{\mathrm{C} 20}^{\prime}-T_{\text {lin }}^{\prime}$ \\
$T 2_{u \nabla T}^{\prime}$ & Reconstructed FUT time series; both $\mathbf{u}_{g}$ and \\
& $\nabla T$ replaced with FUT values \\
$T 2_{\nabla T}^{\prime}$ & Reconstructed FUT time series; $\nabla T$ only \\
& replaced with FUT values \\
$T 2_{u}^{\prime}$ & Reconstructed FUT time series; $\mathbf{u}_{g}$ only \\
$T 3_{u \nabla T}^{\prime}$ & replaced with FUT values \\
$T 3_{\nabla T}^{\prime}$ & $T 2_{u \nabla T}^{\prime}+\epsilon$ \\
$T 3_{u}^{\prime}$ & $T 2_{\nabla T}^{\prime}+\epsilon$ \\
\hline
\end{tabular}

variability in circulation on monthly time scales. In summer, high correlations are restricted to much smaller geographical areas, in particular on the west coast of Europe, northern Africa, North America, and Australia, as well as the Arctic coast. Even in these regions, the variance explained generally does not exceed $40 \%$.

There are various reasons for the spatial and seasonal variation in the fraction of variance explained. First, in regions of high orography (e.g., the Rocky Mountains, Tibetan Plateau, and Andes) geostrophic balance based on SLP is not a good approximation. Indeed, the wind components $u_{g}^{\prime}$ and $v_{g}^{\prime}$ are very poorly correlated with the ESSENCE 10-m wind speed in these regions.

Second, the regression model may not capture the main drivers of variability. For example, in the high Arctic, temperatures are strongly moderated by the radiative budget, and the temperature gradient is very variable such that using the mean temperature gradient is not a good approximation. The difference in correlations in the Northern Hemisphere between summer and winter is particularly striking. This can in many places be attributed to either weaker geostrophic winds in summer (e.g., in western Europe) or weaker temperature gradients in summer (in the North American interior and across the coasts of North America, Norway, and East Asia; Figs. 1a,b). The dominant drivers here are instead the radiative and land surface drivers discussed in the introduction.

\section{c. Use of the simple model to simulate future change: Methodology}

The multiple regression model can be used to investigate what portion of the change in variability discussed in section $3 \mathrm{a}$ can be attributed to changes in thermal advection. A new time series of temperature anomalies is constructed for the future period using the linear model with coefficients $A$ and $B$ retained from the C20 regression and winds and/or temperature gradients calculated from the FUT period of ESSENCE. This is denoted, for example, by $T 2_{u \nabla T}^{\prime}$, with the subscripts denoting whether winds, temperature gradients, or both are changed. To retain a comparable level of noise, the control period time series of $\epsilon$ is then added to create a modeled time series of future temperature anomalies $T 3_{u \nabla T}^{\prime}$. (See Table 2 for a full explanation of notation; $T 2_{u \nabla T}^{\prime}$ is not discussed further.)

The standard deviation of this time series can be compared to $\sigma\left(T_{\mathrm{FUT}}^{\prime}\right)$ (temperature anomalies computed directly from ESSENCE). It is then possible to estimate how much of the projected change in temperature variability in ESSENCE is a direct consequence of thermal advection. By retaining either control period temperature gradients or winds, the contribution to changing temperature variability from wind anomalies and temperature gradients can be partitioned.

This methodology applied directly produces many points at which a nonphysical change in variability is produced (i.e., an increase of greater than double the maximum seen in the ESSENCE data, or a decrease of less than half the minimum). These points are generally those in which the mean control or future temperature gradient is very small (on the order of $1 \times$ $10^{-3} \mathrm{~K} \mathrm{~km}^{-1}$ or less). Therefore any small shift in mean temperature patterns corresponds to a proportional increase or decrease of the gradient of one or two orders of magnitude. This causes an unrealistic change in the reconstructed time series, because temperature anomalies are modeled as a linear function of the gradient components. For this reason any temperature gradient component that is less than $1 \times 10^{-3} \mathrm{~K} \mathrm{~km}^{-1}$ in either period is not included in the regression.

\section{d. Use of the simple model to simulate future change: Results}

Figures $5 \mathrm{c}$ and $5 \mathrm{~d}$ display the change in temperature variability produced by the linear model in the case when only temperature gradients are replaced with their twenty-first-century values (i.e., wind components are retained from the C20 period). Evidently, there are large regions where this is not a good model. In particular, these include the tropics and low- to midlatitude oceans in both seasons, regions of high orography, and the midlatitude continental interiors especially in summer. These regions can be linked back to those where correlation is small in the $\mathrm{C} 20$ period (section 4b), or where temperature gradient changes are small (section 3d). Over Southern Hemisphere midlatitude oceans, the Indian Ocean, and southern 
Eurasia in winter, and over northern China and Eurasia in summer, the model does not even recreate the sign of change correctly. These regions are therefore not considered further.

Figure $5 \mathrm{c}$ shows the results from the linear model for winter. By changing temperature gradients alone, the decrease in winter variability is qualitatively recreated in Alaska and western Canada, the subpolar North Atlantic and much of Europe, the Antarctic Circumpolar Current (ACC) region west of the Drake Passage, and southern Australia. Of these regions, it is of interest to focus on the quantitative agreement for two regions where there is particularly widespread agreement in the sign of change, namely Europe and North America. Figures 5e and $5 \mathrm{~g}$ show this agreement for winter. The agreement is quantified by $\left[\sigma\left(T 3_{\nabla T}^{\prime}\right)-\sigma\left(T_{\mathrm{C} 20}^{\prime}\right)\right] /\left[\sigma\left(T 3_{\mathrm{FUT}}^{\prime}\right)-\sigma\left(T_{\mathrm{C} 20}^{\prime}\right)\right]$. Therefore, a value less than 0 (dark blue) implies that the linear model sign of change is incorrect, and a value of 1 (white) that implies the linear model recreates the exact magnitude of change. Over much of Europe and large regions of North America, over $50 \%$ of the projected change in variability can be reproduced solely using the change in mean temperature gradient.

Over the ocean there are regions where the linear model future variability is over a factor of 2 greater than that simulated in ESSENCE. These are regions of decreasing variability; therefore the discrepancy implies that much of the decrease is caused by processes not accounted for in the linear model. Comparison with Fig. 2 shows that these regions are those just inside the control period sea ice zone. This is discussed in the next section.

In summer (Fig. 5d), the linear model induces the largest changes at the coasts (excluding that of Antarctica) and in high latitudes of the Northern Hemisphere $\left(70^{\circ}-80^{\circ} \mathrm{N}\right)$. There is also a strong signal inland in northern Africa and over much of Europe. The linear model correctly reproduces increasing variability in Australia, Europe and northern Africa, India and South America, and off the Arctic coast. There is also scattered agreement elsewhere, but often in regions where the change simulated by ESSENCE is small. In subpolar regions (poleward of $60^{\circ}$ ) the linear model again underestimates the projected changes. Increasing variability in other areas is generally undersimulated, in particular in India and South America, off the Arctic coast, and to a small extent in parts of Europe. Figures $5 f$ and $5 \mathrm{~h}$ show the agreement between the linear model and ESSENCE for summer. Evidently the linear model is less skillful in summer than winter, but there are still areas, including southern England, southern Spain, and central Europe, where the change in temperature gradient reproduces $50 \%$ of the future change in variability. Thermal advection does not appear to be an important process in changing variability in North America in summer.

Circulation changes may also contribute to changes in advection. ECHAM5 (the atmospheric model in ESSENCE) shares many features of circulation change with other models. These include a poleward shift of the westerlies in the Southern Hemisphere in both seasons and in the Pacific in winter and a downstream extension of the Atlantic storm track (not shown; e.g., Pinto et al. 2007). Figure 6 shows which of the variability changes described above are reproduced when circulation $\mathbf{u}_{g}$ is changed in addition to or instead of temperature gradients. The change induced by circulation changes and temperature gradients together (Fig. 6, top) is in the opposite sense to that in the full simulation across much of the subtropical Southern Hemisphere ocean. The change induced by circulation changes only is very small (Fig. 6, bottom), so we conclude that temperature gradients are more important for explaining future changes in variability.

Since the Arctic is a region of distinctive changes in temperature variability that are qualitatively but not quantitatively recreated by the simple linear model, and given the role of Arctic amplification in changing temperature gradients, we now discuss the Arctic region in more detail.

\section{e. Arctic regions}

The low correlations in the Arctic (Figs. 5a,b) suggest that circulation variability is not a key driver of surface temperature variability here. As is the case anywhere, this could be due either to dynamical terms neglected in the regression, which include variability in $\nabla T$, or to thermodynamic effects. High temperature gradients across the ice edge and the intraseasonal movement of this edge causes high variability in gradients themselves, and so if dynamics are the cause it could be expected that including $\nabla T^{\prime}$ in the regression would increase correlations and the ability of the regression to reproduce future change. This can be done either within the regression components [so that, e.g., $u_{g}^{\prime}(\partial \bar{T} / \partial x)$ becomes $\left.u_{g}^{\prime}(\partial T / \partial x)\right]$ or by fitting the model separately to $u_{g}^{\prime}$ and $\partial T^{\prime} / \partial x$. However, sensitivity tests (not shown) confirmed that neither method notably improves correlations in the Arctic region, except between $30^{\circ} \mathrm{W}$ and $60^{\circ} \mathrm{E}$, a region where the simpler description of thermal advection variability was already producing good results.

This is consistent with (in winter) temperatures in the Atlantic sector being dominated by thermal advection but elsewhere across Arctic being dominated by the 
a) Winter SD change FUT u, FUT $\nabla T$
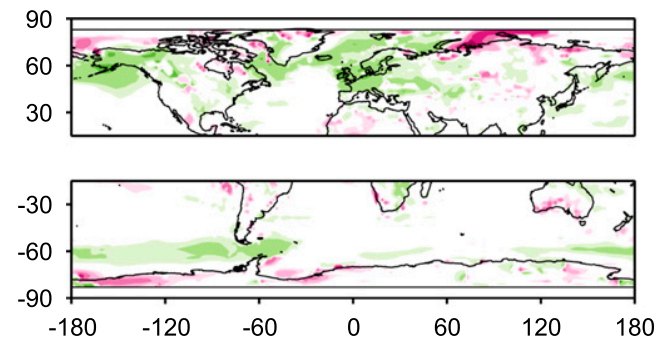

c) Winter SD change FUT u, C20 VT
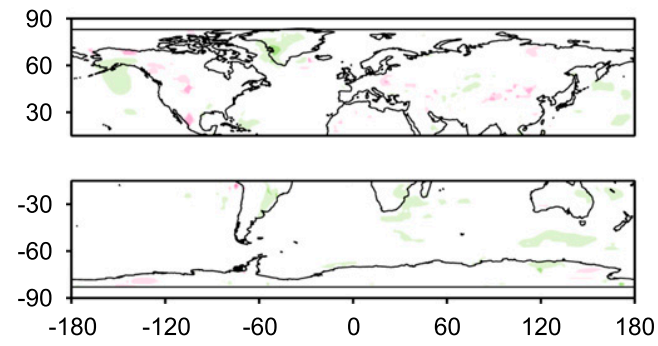

FIG. 6. As in Figs. 5c and 5d, but with (top) $\sigma\left(T 3_{u \nabla T}^{\prime}\right) / \sigma\left(T_{\mathrm{C} 20}^{\prime}\right)$ and (bottom) $\sigma\left(T 3_{u}^{\prime}\right) / \sigma\left(T_{\mathrm{C} 20}^{\prime}\right)$. b) Summer SD change FUT u, FUT $\nabla T$

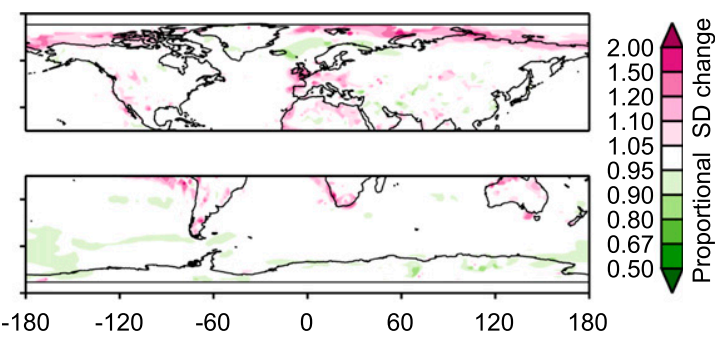

d) Summer SD change FUT u, C20 VT

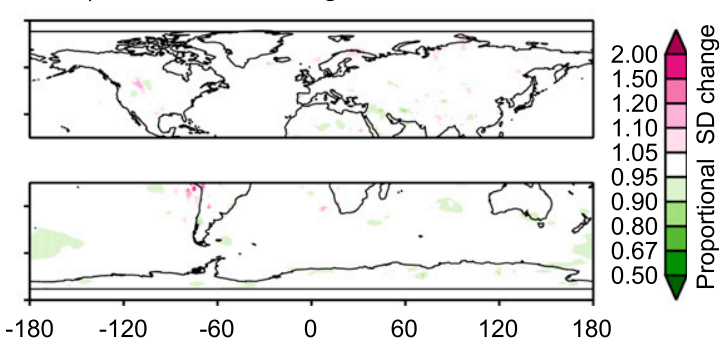

longwave radiation budget (Serreze and Barry 2005). The longwave radiation budget is affected by the extent and depth of sea ice cover as well as the amount and type of cloud cover.

\section{f. Daily variability}

A preliminary analysis of variability, its changes, and the twentieth-century relationship with thermal advection was also conducted for ESSENCE daily data. These results are summarized below (not shown).

As expected, the C20 standard deviations of daily data are larger than monthly values. The seasonal and spatial structure is similar, with greater variability in winter, and at high latitudes or over sea ice, snow, land, and the western boundary currents in the ocean. Some features differ; for example, the local maximum in monthly variability in the equatorial Pacific, which can be linked to ENSO, is not as prominent in daily data. The changes are also consistent with the findings in monthly data, although changes in daily variability are weaker in the Arctic and stronger over Eurasia than in the monthly data.

Finally, the correlations between geostrophic winds and temperature are lower on daily time scales than on monthly time scales; in daily data, while correlations still exceed 0.6 in some regions, summer correlations in the Northern Hemisphere are particularly low $(<0.4$ everywhere). Therefore, the relative importance of different processes for daily variability is, as may be expected, somewhat different than for monthly variability.
A detailed analysis of processes acting on daily time scales is left for future work.

\section{Discussion and conclusions}

In this paper we have presented a global assessment of the climatological variability of monthly and to a lesser extent daily temperatures in the two solstitial seasons, projected changes, and the role of the thermal advection mechanism. The key findings may be summarized as follows:

- There is a clear spatial pattern and seasonality in the projected changes of the standard deviation $\sigma$ of monthly surface air temperature variability. This is robust across a single model initial condition ensemble (Fig. 2). Many of these changes are also robust across the CMIP5 multimodel ensemble (Fig. 4).

- The time series of $\sigma$ averaged over a large region (Fig. 3) is noisy, showing the importance of good sampling, such that the use of a large ensemble as is done in this paper is essential.

- A simple metric of atmospheric thermal advection explains over $50 \%$ of twentieth-century monthly temperature variability in widespread areas in winter (Fig. 5c).

- A relatively simple regression model, taking account only of changes in mean temperature gradients, is able to reproduce many aspects of the spatial pattern of change. Over large regions of Europe and North America in winter the advection could account for 
over half of the projected change in temperature variability. The contribution is weaker in summer but still amounts to several tens of percent over large regions (Figs. 5e-h). This suggests that the thermal advection mechanism, whereby anomalous winds blowing across a region of temperature gradation cause anomalous temperatures downstream, provides a physical explanation for many of the projected changes in temperature variability.

Regarding the variability changes themselves, preliminary analysis found similar results for daily variability. Robust signals of change in the large ESSENCE ensemble thus add weight to recent papers by Ylhäisi and Räisänen (2014), Screen (2014), and Schneider et al. (2015) demonstrating changes in daily variability. Emergence of the signal is not expected until at least the middle of the twenty-first century. Moreover, regions where results are robust in ESSENCE but not in CMIP5 point to the role of structural differences between models, rather than internal variability, in the uncertainty. Moreover, in the CMIP5 models, changes in seasonality play a large role in the model uncertainty and in the changes in standard deviation.

For winter, our findings on the role of thermal advection are consistent with the link between variability and zonal gradients proposed by de Vries et al. (2012), and between variability and Arctic amplification as shown by Screen (2014) and Schneider et al. (2015). All these papers look at a specific domain (Europe or the Northern Hemisphere) and at a specific temperature gradient direction, whereas our model is successful over a large spread of geographic regions and covers both directions. Moreover, we explicitly recreate future changes in variability using changed temperature gradients, which no previous study has done. Thermal advection is found to be important for projected changes in Alaska, western Canada, Europe, southern Australia, and subpolar oceans in winter.

In summer, local radiative and land surface processes are more often invoked to explain changes in variability, with some exceptions; Watterson et al. (2008) showed that projected changes in summer temperature extremes in south central Australia can be understood in terms of thermal advection from the hot continental interior, using a simple model with some similarities to ours. They concluded that it is the increasing temperature gradient, and not changes in wind variability, that dominate the response. Our results also show a role of the temperature gradient and thermal advection for Australia in summer, but in the southeast (Fig. 5d). We also find other regions where the effect of temperature gradients can be seen in summer, for example in Europe, subtropical land areas, and off the Arctic coast.
However, the change induced by the thermal advection mechanism is, in most areas, less than $50 \%$ of the whole, with the local radiative and land surface processes discussed previously playing a more dominant role.

The regression model is deliberately simple and yet is able to capture a large proportion of projected changes in temperature variability. It is to be expected that some of the choices made may have moderate effects on the findings; for example, the influence of the land-sea contrast on variability near coasts may extend further inland were a different length scale used.

The thermal advection mechanism discussed in this paper would manifest as changes in the relationships between circulation and temperature anomalies, as found in Goubanova et al. (2010) and Masato et al. (2014). For example, the familiar temperature impacts of given circulation regimes such as the cold weather found in northern Europe in the negative phase of the North Atlantic Oscillation may become less severe in winter due to reduced temperature gradients (Cattiaux et al. 2010; Osborn 2011; Masato et al. 2014; Dong et al. 2011). Cattiaux et al. (2012) found that in each season, circulation changes (assuming the same relationship between circulation and temperature) are not the dominant driver of future warming and of increases in interannual variability. This is consistent with the findings above that temperature gradient changes are more important than circulation changes. These results therefore have important implications for understanding the impacts of circulation patterns in the future, as well as contributing to the ongoing discussion about extremes in a more statistical sense. Crucially, changes predicted by the thermal advection mechanism as outlined in this study can be treated with added confidence due to the physical understanding underlying heterogeneous changes in mean surface temperature.

Acknowledgments. We thank the two anonymous reviewers for their comments, which enabled us to greatly improve the manuscript. We acknowledge the World Climate Research Programme's Working Group on Coupled Modelling, which is responsible for CMIP, and we thank the climate modeling groups (listed in Table 1 of this paper) for producing and making available their model output. For CMIP the U.S. Department of Energy's Program for Climate Model Diagnosis and Intercomparison provides coordinating support and led development of software infrastructure in partnership with the Global Organization for Earth System Science Portals. CH was funded by a NERC PhD studentship at the University of Reading. EH was supported by the APPOSITE project (Grant NE/I029447/1), funded by the U.K. Natural Environment Research Council. 


\section{REFERENCES}

Barlow, R. J., 1989: Statistics: A Guide to the Use of Statistical Methods in the Physical Sciences. John Wiley \& Sons, 204 pp.

Boer, G. J., 2011: The ratio of land to ocean temperature change under global warming. Climate Dyn., 37, 2253-2270, doi:10.1007/s00382-011-1112-3.

Cattiaux, J., R. Vautard, C. Cassou, P. Yiou, V. Masson-Delmotte, and F. Codron, 2010: Winter 2010 in Europe: A cold extreme in a warming climate. Geophys. Res. Lett., 37, L20704, doi:10.1029/2010GL044613.

_, P. Yiou, and R. Vautard, 2012: Dynamics of future seasonal temperature trends and extremes in Europe: A multi-model analysis from CMIP3. Climate Dyn., 38, 1949-1964, doi:10.1007/s00382-011-1211-1.

Collins, M., and Coauthors, 2013: Long-term climate change: Projections, commitments and irreversibility. Climate Change 2013: The Physical Science Basis, T. F. Stocker et al., Eds., Cambridge University Press, 1029-1136.

de Vries, H., R. J. Haarsma, and W. Hazeleger, 2012: Western European cold spells in current and future climate. Geophys. Res. Lett., 39, L04706, doi:10.1029/2011GL050665.

Dong, B., R. Sutton, and T. Woollings, 2011: Changes of interannual NAO variability in response to greenhouse gases forcing. Climate Dyn., 37, 1621-1641, doi:10.1007/s00382-010-0936-6.

Fischer, E. M., and C. Schär, 2009: Future changes in daily summer temperature variability: Driving processes and role for temperature extremes. Climate Dyn., 33, 917-935, doi:10.1007/ s00382-008-0473-8.

— J. Rajczak, and C. Schär, 2012: Changes in European summer temperature variability revisited. Geophys. Res. Lett., 39, L19702, doi:10.1029/2012GL052730.

Goubanova, K., L. Li, P. Yiou, and F. Codron, 2010: Relation between large-scale circulation and European winter temperature: Does it hold under warmer climate? J. Climate, 23, 3752-3760, doi:10.1175/2010JCLI3166.1.

Gregory, J. M., and J. F. B. Mitchell, 1995: Simulation of daily variability of surface temperature and precipitation over Europe in the current and $2 \times \mathrm{CO}_{2}$ climates using the UKMO climate model. Quart. J. Roy. Meteor. Soc., 121, 1451-1476, doi:10.1002/qj.49712152611.

Hartmann, D. L., and Coauthors, 2013: Observations: Atmosphere and surface. Climate Change 2013: The Physical Science Basis, T. F. Stocker et al., Eds., Cambridge University Press, 159-254.

Hawkins, E., and R. Sutton, 2012: Time of emergence of climate signals. Geophys. Res. Lett., 39, L01702, doi:10.1029/ 2011 GL050087.

Joshi, M. M., J. M. Gregory, M. J. Webb, D. M. H. Sexton, and T. C. Johns, 2008: Mechanisms for the land/sea warming contrast exhibited by simulations of climate change. Climate Dyn., $\mathbf{3 0}$, 455-465, doi:10.1007/s00382-007-0306-1.

Kang, S. M., R. Seager, D. M. Frierson, and X. Liu, 2015: Croll revisited: Why is the Northern Hemisphere warmer than the Southern Hemisphere? Climate Dyn., 44, 1457-1472, doi:10.1007/s00382-014-2147-z.

Katz, R. W., and B. G. Brown, 1992: Extreme events in a changing climate: Variability is more important than averages. Climatic Change, 21, 289-302, doi:10.1007/BF00139728.

Lenderink, G., A. van Ulden, B. van den Hurk, and E. van Meijgaard, 2007: Summertime inter-annual temperature variability in an ensemble of regional model simulations: Analysis of the surface energy budget. Climatic Change, 81, 233-247, doi:10.1007/s10584-006-9229-9.

Masato, G., T. Woollings, and B. J. Hoskins, 2014: Structure and impact of atmospheric blocking over the Euro-Atlantic region in present-day and future simulations. Geophys. Res. Lett., 41, 1051-1058, doi:10.1002/2013GL058570.

Osborn, T. J., 2011: Winter 2009/2010 temperatures and a recordbreaking North Atlantic Oscillation index. Weather, 66, 19-21, doi:10.1002/wea.660.

, D. Conway, M. Hulme, J. M. Gregory, and P. D. Jones, 1999: Air flow influences on local climate: Observed and simulated mean relationships for the United Kingdom. Climate Res., 13, 173-191, doi:10.3354/cr013173.

Parker, D. E., 2009: Anomalies of central England temperature classified by air source. J. Climate, 22, 1069-1081, doi:10.1175/ 2008JCLI2250.1.

— T. P. Legg, and C. K. Folland, 1992: A new daily central England temperature series, 1772-1991. Int. J. Climatol., 12, 317-342, doi:10.1002/joc.3370120402.

Peings, Y., J. Cattiaux, and H. Douville, 2013: Evaluation and response of winter cold spells over western Europe in CMIP5 models. Climate Dyn., 41, 3025-3037, doi:10.1007/ s00382-012-1565-z.

Pfahl, S., and H. Wernli, 2012: Quantifying the relevance of atmospheric blocking for co-located temperature extremes in the Northern Hemisphere on (sub-)daily time scales. Geophys. Res. Lett., 39, L12807, doi:10.1029/2012GL052261.

Pinto, J., U. Ulbrich, G. Leckebusch, T. Spangehl, M. Reyers, and S. Zacharias, 2007: Changes in storm track and cyclone activity in three SRES ensemble experiments with the ECHAM5/ MPI-OM1 GCM. Climate Dyn., 29, 195-210, doi:10.1007/ s00382-007-0230-4.

Rowell, D. P., 2005: A scenario of European climate change for the late twenty-first century: Seasonal means and interannual variability. Climate Dyn., 25, 837-849, doi:10.1007/s00382-005-0068-6.

Schär, C., P. L. Vidale, D. Lüthi, C. Frei, C. Häberli, M. A. Liniger, and C. Appenzeller, 2004: The role of increasing temperature variability in European summer heatwaves. Nature, 427, 332336, doi:10.1038/nature02300.

Scherrer, S. C., C. Appenzeller, M. A. Liniger, and C. Schär, 2005: European temperature distribution changes in observations and climate change scenarios. Geophys. Res. Lett., 32, L19705, doi:10.1029/2005GL024108.

Schneider, T., T. Bischoff, and H. Płotka, 2015: Physics of changes in synoptic midlatitude temperature variability. J. Climate, $\mathbf{2 8}$, 2312-2331, doi:10.1175/JCLI-D-14-00632.1.

Screen, J. A., 2014: Arctic amplification decreases temperature variance in northern mid- to high-latitudes. Nat. Climate Change, 4, 577-582, doi:10.1038/nclimate2268.

— , and I. Simmonds, 2010: The central role of diminishing sea ice in recent arctic temperature amplification. Nature, 464, 13341337, doi:10.1038/nature09051.

Seneviratne, S. I., D. Lüthi, M. Litschi, and C. Schär, 2006: Landatmosphere coupling and climate change in Europe. Nature, 443, 205-209, doi:10.1038/nature05095.

Serreze, M. C., and R. G. Barry, 2005: The Arctic Climate System. Cambridge University Press, $385 \mathrm{pp}$.

Sterl, A., and Coauthors, 2008: When can we expect extremely high surface temperatures? Geophys. Res. Lett., 35, L14703, doi:10.1029/2008GL034071.

Stott, P. A., D. A. Stone, and M. R. Allen, 2004: Human contribution to the European heatwave of 2003. Nature, 432, 610614, doi:10.1038/nature03089. 
Stouffer, R. J., and R. T. Wetherald, 2007: Changes of variability in response to increasing greenhouse gases. Part I: Temperature. J. Climate, 20, 5455-5467, doi:10.1175/2007JCLI1384.1.

van Ulden, A. P., and G. J. van Oldenborgh, 2006: Large-scale atmospheric circulation biases and changes in global climate model simulations and their importance for climate change in central Europe. Atmos. Chem. Phys., 6, 863-881, doi:10.5194/ acp-6-863-2006.

van Vuuren, D. P., and Coauthors, 2011: The representative concentration pathways: An overview. Climatic Change, 109, 5-31, doi:10.1007/s10584-011-0148-z.
Vidale, P., D. Lüthi, R. Wegmann, and C. Schär, 2007: European summer climate variability in a heterogeneous multi-model ensemble. Climatic Change, 81, 209-232, doi:10.1007/ s10584-006-9218-z.

Watterson, I. G., J. L. McGregor, and K. C. Nguyen, 2008: Changes in extreme temperatures of Australasian summer simulated by CCAM under global warming, and the roles of winds and land-sea contrasts. Aust. Meteor. Mag., 57, 195-212.

Ylhäisi, J. S., and J. Räisänen, 2014: Twenty-first century changes in daily temperature variability in CMIP3 climate models. Int. J. Climatol., 34, 1414-1428, doi:10.1002/joc.3773. 